\title{
Teknik Resampling untuk Mengatasi Ketidakseimbangan Kelas pada Klasifikasi Penyakit Diabetes Menggunakan C4.5, Random Forest, dan SVM
}

Resampling Technique for Handling Class Imbalance in the Classification of Diabetes using C4.5, Random Forest, and SVM

Wahyu Nugraha ${ }^{1}$, Raja Sabaruddin ${ }^{2}$

${ }^{1,2}$,Fakultas Teknik dan Informatika, Universitas Bina Sarana Informatika PSDKU Pontianak

E-mail: ${ }^{1}$ wahyu.whn@bsi.ac.id, ${ }^{2}$ raja.rjd@bsi.ac.id

\begin{abstract}
Abstrak
Penderita diabetes di seluruh dunia terus mengalami peningkatan dengan angka kematian sebesar 4,6 juta pada tahun 2011 dan diperkirakan akan terus meningkat secara global menjadi 552 juta pada tahun 2030. Pencegahan Penyakit diabetes mungkin dapat dilakukan secara efektif dengan cara mendeteksinya sejak dini. Data mining dan machine learning terus dikembangkan agar menjadi alat yang handal dalam membangun model komputasi untuk mengidentifikasi penyakit diabetes pada tahap awal. Namun, masalah yang sering dihadapi dalam menganalisis penyakit diabetes ialah masalah ketidakseimbangan class. Kelas yang tidak seimbang membuat model pembelajaran akan sulit melakukan prediksi karena model pembelajaran didominasi oleh instance kelas mayoritas sehingga mengabaikan prediksi kelas minoritas. Pada penelitian ini kami mencoba menganalisa dan mencoba mengatasi masalah ketidakseimbangan kelas dengan menggunakan pendekatan level data yaitu teknik resampling data. Eksperimen ini menggunakan R language dengan library ROSE (version 0.0-4). Dataset Pima Indians dipilih pada penelitian ini karena merupakan salah satu dataset yang mengalami ketidakseimbangan kelas. Model pengklasifikasian pada penelitian ini menggunakan algoritma decision tree C4.5, RF (Random Forest), dan SVM (Support Vector Machines). Dari hasil eksperimen yang dilakukan model klasifikasi SVM dengan teknik resampling yang menggabungkan over dan under-sampling menjadi model yang memiliki performa terbaik dengan nilai AUC (Area Under Curve) sebesar 0.80
\end{abstract}

Kata kunci: Resampling, Ketidakseimbangan Kelas, Klasifikasi, Area Under Curve (AUC)

\begin{abstract}
People with diabetes worldwide continue to experience an increase with a death rate of 4.6 million in 2011 and is expected to continue to increase globally to 552 million by 2030. Prevention of diabetes may be done effectively by detecting it early. However, the problem that is often faced in analyzing diabetes is the class imbalance problem. An unbalanced class makes it difficult for the learning model to make predictions because the learning model is dominated by instances of the majority class, thus ignoring the predictions of the minority class. In this study, we try to analyze and try to overcome the problem of class imbalance by using a data level approach, namely data resampling techniques. This experiment uses the $R$ language with the ROSE library (version 0.0-4). The Pima Indians dataset was chosen in this study because it is one of the datasets that experience class imbalance. The classification model in this study uses the decision tree algorithm C4.5, RF (Random Forest), and SVM (Support Vector Machines). From the results of experiments conducted on the SVM classification model with a resampling technique that combines over and under-sampling into a model that has the best performance with an AUC (Area Under Curve) value of 0.80
\end{abstract}

Keywords: Resampling, Class Imbalance, Classification, Area Under Curve (AUC) 


\section{PENDAHULUAN}

Terdapat 347 juta penderita diabetes di seluruh dunia dengan angka kematian sebesar 4,6 juta pada tahun 2011 yang disebakan oleh penyakit diabetes. Jumlah penderita diabetes diperkirakan akan terus meningkat secara global menjadi 552 juta pada tahun 2030 dan diperkirakan akan menjadi peringkat ketujuh penyebab utama kematian [1]. Menurut International Diabetes Federation (IDF) jumlah penderita diabetes mendekati 463 juta. Angka tersebut diperoleh dari hasil surver pada tahun 2019, bahkan peneliti memperkirakan jumlah penderita diabetes bisa terus meningkat menjadi 642 juta [2]. Selain itu, Organisasi Kesehatan Dunia atau disingkat WHO menyatakan bahwa ada sekitar 1,6 juta orang meninggal diakibatkan oleh diabetes setiap tahunnya [3]. Diabetes merupakan salah satu penyakit yang disebabkan oleh kadar gula darah pada tubuh manusia sangat tinggi. Penyakit diabetes terjadi ketika penkreas tidak cukup untuk memproduksi insulin atau biasa disebut diabetes tipe 1. Akan tetapi, ketika tubuh tidak dapat menggunakan insulin dengan baik maka ini disebut sebagai diabetes tipe 2 [2][3]. Pencegahan Penyakit diabetes mungkin dapat dilakukan secara efektif dengan cara mendeteksinya sejak dini sehingga orang akan menjalankan pola hidup sehat untuk mencegah penyakit diabetes [4]. Data mining dan machine learning terus dikembangkan agar menjadi alat yang handal dalam membangun model komputasi untuk mengidentifikasi penyakit diabetes pada tahap awal [5].

Algoritma machine learning dapat menemukan pola pembelajaran tertentu dari dataset sehingga dapat melakukan prediksi dengan cukup akurat terhadap penyakit diabetes [3]. Namun, masalah utama yang sering terjadi dalam menganalisis data medis adalah masalah ketidakseimbangan class. Sebuah dataset bisa dianggap tidak seimbang jika kategori klasifikasi sangat kurang terwakili atau distribusi kelas sangat tidak seimbang [6]. Beberapa penelitian sebelumnya telah menggunakan metode machine learning untuk memprediksi penyakit diabetes menggunakan dataset Pima Indian diabetes karena merupakan salah satu dataset yang mengalami ketidakseimbangan kelas [3]. Dataset Pima Indian diperoleh dari repositori UCI yang memiliki 9 attribut dengan total data sebanyak 768 data [7]. Ketidakseimbangan class pada dataset membuat model pembelajaran akan sulit melakukan prediksi karena model pembelajaran didominasi oleh instance kelas mayoritas sehingga mengabaikan prediksi kelas minoritas [8]. Metode untuk mengatasi ketidakseimbangan kelas dibagi menjadi empat pendekatan, yaitu: algorithmic level, cost-sensitive, data level, dan ensembles of classifiers [9]. Pendekatan level data banyak menjadi bahan pertimbangan untuk penelitian pada berbagai literatur [10]. Namun, akan sangat sulit untuk menentukan rasio resampling yang optimal secara otomatis [9].

Resampling merupakan teknik dengan pendekatan level data yang digunakan untuk mengatasi ketidakseimbangan kelas dengan mengeliminasi beberapa data dari kelas mayoritas (undersampling) atau menambahkan beberapa data menggunakan hasil dari proses generated atau duplikat data ke kelas minoritas (oversampling) [11]. Salah satu teknik oversampling yang cukup berhasil dalam menghasilkan data baru dari kelas minoritas adalah SMOTE (Synthetic Minority Over-sampling Technique). Metode sampling lain dapat digunakan untuk mengatasi masalah ketidakseimbangan kelas salah satunya dengan menggabungkan teknik over-sampling dan under-sampling secara bersamaan dengan cara menghapus kelebihan dari kelas mayoritas dan menambahkan jumlah kelas minoritas sehingga menghasilkan distribusi kelas yang seimbang [7].

Pada penelitian ini kami mencoba menganalisa dan mencoba mengatasi masalah ketidakseimbangan kelas dengan menggunakan pendekatan level data yaitu teknik resampling data. Eksperimen ini menggunakan $R$ language dengan library ROSE (version 0.0-4) di mana pada library tersebut terdapat metode resampling seperti over-sampling, under-sampling, combination of over- and under-sampling serta Generation of synthetic data by Randomly Over Sampling Examples (ROSE). Keempat metode sampling ini akan digunakan untuk mengatasi masalah ketidak seimbangan kelas pada dataset Pima Indian. Model pengklasifikasian pada penelitian ini menggunakan algoritma decision tree C4.5, RF (Random Forest), dan SVM (Support Vector Machines). Dari hasil eksperimen yang dilakukan akan dilakukan komparasi 
secara keseluruhan untuk mencari model terbaik berdasarkan hasil mengukuran. Pengukuran terhadap performa model menggunakan nilai Area Under Curve (AUC) yang diperoleh dari tabel confusion matrix. Confusion matrix dapat memberikan penilaian kinerja model klasifikasi berdasarkan jumlah objek yang diprediksi dengan benar dan salah agar didapat nilai akurasi, sensitivity, specificity dan Area Under Curve (AUC) [12].

\section{METODE PENELITIAN}

\subsection{Pengumpulan Data}

Dataset yang digunakan dalam penelitian ini adalah data yang terkait penyakit diabetes dan juga terkait dengan masalah ketidakseimbangan kelas. Dataset yang digunakan berasal dari Kaggle dataset repository (UCI Pima Indians Diabetes Database) yang diunduh dari https:/www.kaggle.com/uciml/pima-indians-diabetes-database. Dataset ini memiliki 9 attribut dengan total sampel valid sebanyak 768 sample. Nilai attribut dataset ini berasal dari semua wanita berusia minimal 21 tahun [1]. Dataset terdiri dari 8 variabel prediktor medis dan satu variabel target yaitu Outcome. Penelitian lain yang telah menggunakan dataset Pima Indians ini diantaranya dilakukan oleh Kumar dengan penelitian mengenai prediksi penyakit diabetes melitus menggunakan Deep Neural Networks classifier [2], Khanam dengan penelitian mengenai perbandingan algoritma machine learning untuk memprediksi penyakit diabetes [3], dan Hayashi dengan penelitian mengenai Rule extraction menggunakan algoritma RecursiveRule extraction dengan J48graft yang dikombinasikan teknik pemilihan sampel untuk diagnosis penyakit diabetes melitus tipe 2 pada dataset Pima Indians [1].

\subsection{Data Preparation}

Data preparation bertujuan untuk mendapatkan data yang siap diolah dan berkualitas baik [13]. Beberapa teknik data preparation diantaranya:

1. Data validation digunakan untuk untuk mengatasi masalah Incompleteness atau data yang mengalami missing value. Gambar 1 menunjukkan hasil eksekusi bahwa dataset ini sudah tidak ditemukan adanya missing value.



Gambar 1 Contoh Data Tanpa Missing Value 
2. Data integration dan transformation, Data yang bernilai kategorikal ditransformasikan ke dalam angka misalkan seperti attribut Outcome (positive, negative) diubah kedalam bentuk angka $(0,1)$. Selain itu konversi tipe data ke bentuk format numerik juga diperlukan agar dataset dapat diuji coba menggunakan model klasifikasi. Gambar 2 menunjukkan bahwa data telah siap digunakan.



Gambar 2 Contoh Data yang Sudah Siap Diuji

\subsection{Ketidakseimbangan Kelas (Class Imbalance)}

Ketidakseimbangan kelas maksudnya adalah dataset yang menunjukkan perbedaan yang signifikan antara kelas yang satu dengan yang lainnya. Secara umum pemahaman tentang ketidakseimbangan kelas berkaitan dengan situasi dimana beberapa instance kelas dari data sangat tidak terwakili jika dibandingkan dengan kelas yang lain [14]. Penelitian mengenai imbalanced class sering menganggap bahwa rata-rata jumlah minoritas class $10 \%$ sampai $20 \%$. Kenyataannya, dataset biasanya jauh lebih tidak seimbang.

\subsection{Pemodelan}

Pada penelitian ini untuk mengatasi masalah ketidakseimbangan kelas diusulkan model dengan pendekatan level data yaitu menggunakan 4 teknik resampling yang terdapat pada package ROSE: A Package for Binary Imbalanced Learning pada R language. Gambaran dari kerangka pemikiran atau model tahapan penelitian dapat dilihat pada Gambar 3.

Eksperimen yang dilakukan pada dataset diabetes harus dilakukan secara adil terutama dalam menentukan rasio resampling yang optimal pada semua pengujian. Jadi semua data training pada dataset persentase imbalance datanya harus cukup imbang. Perbandingan jumlah antara kelas mayoritas dan minoritas data training pada dataset diabetes Pima Indian ditunjukkan pada Tabel 1. Hasil pengujian akan diukur menggunakan confusion matrix atau matrik konfusi ysng dapat dilihat pada Tabel 2 untuk mendapatkan nilai akurasi, sensitivity, specificity dan Area Under Curve (AUC) yang dinyatakan dalam pernyataan 1, 2, 3, dan 4. Confusion matrix memberikan penilaian kinerja model klasifikasi berdasarkan jumlah objek yang diprediksi dengan benar dan salah [12]. 
Techno.COM, Vol. 20, No. 3, Agustus 2021: 352-361



Gambar 3 Model Tahapan Penelitian

Tabel 1 Rasio Imbalance Class Training Set Pima Indian

\begin{tabular}{|c|c|c|}
\hline \multirow{2}{*}{ Metode Sampling } & \multicolumn{2}{|c|}{ Jumlah instance } \\
\cline { 2 - 3 } & Positif & Negatif \\
\hline Original & 206 & 409 \\
\hline Over-sampling & 401 & 409 \\
\hline Under-sampling & 206 & 204 \\
\hline Both & 296 & 319 \\
\hline ROSE & 296 & 319 \\
\hline
\end{tabular}

Tabel 1 Model Confusion Matrix

\begin{tabular}{|c|c|c|c|}
\hline Classification & \multicolumn{3}{|c|}{ Predicted Class } \\
\hline \multirow{3}{*}{ Observed Class } & & Class $=Y E S$ & Class $=N O$ \\
\hline & Class $=Y E S$ & $\begin{array}{c}\mathbf{A} \\
\text { (true positive-TP) }\end{array}$ & $\begin{array}{c}\text { B } \\
\text { (false negative-FN) }\end{array}$ \\
\hline & Class $=N O$ & $\begin{array}{c}\mathbf{C} \\
\text { (false positive-FP) }\end{array}$ & $\begin{array}{c}\text { D } \\
\text { (true negative-TN) }\end{array}$ \\
\hline
\end{tabular}

$$
\begin{gathered}
\text { Accuracy }=\frac{T P+T N}{T P+T N+F P+F N} \\
\text { Sensitivity }=\frac{T P}{T P+F P} \\
\text { Specificity }=\frac{T N}{F N+T N}
\end{gathered}
$$




$$
\text { Balanced Accuracy } / A U C=\frac{\text { Sensitivity }+ \text { Specificity }}{2}
$$

\subsection{Validation and Evaluation Model}

Model validasi untuk learning dan testing menggunakan 10 fold cross-validation. Data training dibagi menjadi 10 bagian yang sama kemudian proses pembelajaran (learning) dilakukan sebanyak jumlah k yaitu 10 kali. Dari Tabel 3 dapat dilihat bahwa setiap kali dipilih satu bagian sebagai data testing. Maka, data yang lain sebanyak 9 bagian digunakan sebagai data pembelajaran (learning). Setelah itu, dihitung nilai rata-rata dan nilai penyimpangan (deviation value) dari 10 kali jumlah pengujian yang berbeda [15]. Penelitian ini menggunakan $k$-fold cross validation karena metode ini telah menjadi metode validasi standar dan state-of-theart [16].

Evaluasi terhadap kinerja model pada eksperimen ini menggunakan area under curve $(A U C)$ sebagai indikator penentu performa dari model klasifikasi. Data yang diuji baik yang benar maunpun yang salah dihitung menggunakan confusion matrix. Dari tabel konfusi ini nantinya diperoleh nilai penunjang lain diantaranya akurasi, sensitivity, specificity, dan Area Under Curve (AUC). Lessmann menganjurkan penggunaan AUC untuk meningkatkan crossstudy comparability [17]. Nilai AUC pada masing-masing dataset digunakan sebagai penentuan metode yang menghasilkan akurasi yang paling tinggi. Penggunaan nilai AUC sebagai bahan evaluasi kinerja model disajikan oleh Gorunescu [15]. Interpretasi dari klasifikasi nilai AUC terhadap pengujian dapat dilihat pada Tabel 4.

Tabel 2 Stratified 10 Fold Cross Validation

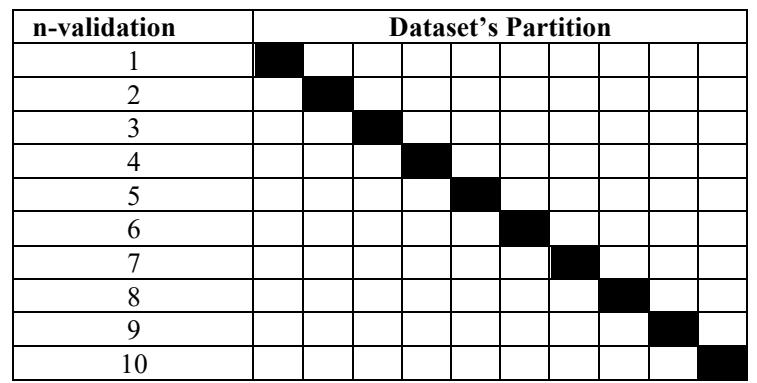

Tabel 3 Klasifikasi Nilai AUC

\begin{tabular}{|c|c|}
\hline Nilai AUC & Klasifikasi \\
\hline $0.9-1$ & Excellent classification \\
\hline $0.8-0.9$ & Good classification \\
\hline $0.7-0.8$ & Fair classification \\
\hline $0.6-0.7$ & Poor classification \\
\hline$<0.6$ & Failure \\
\hline \multicolumn{2}{|c}{} \\
\hline
\end{tabular}

\section{HASIL DAN PEMBAHASAN}

Penerapan metode klasifikasi C4.5, Random Forest dan SVM pada dataset dilakukan apa adanya tanpa proses sampling. Kemudian akan dibandingkan dengan model yang menggunakan teknik sampling yang ada pada library rose pada $R$ language seperti oversampling, under-sampling, kombinasi dari over-sampling dan under-sampling serta Generation of synthetic data by Randomly Over Sampling Examples. Dari hasil pengujian yang telah dilakukan diperoleh nilai confusion matrix dari masing-masing algoritma klasifikasi yang dapat dilihat pada tabel 5, tabel 6, dan tabel 7. Nilai yang diperoleh dari matriks konfusi adalah akurasi, sensitivity, specificity dan Area Under Curve. Penelitian ini fokus pada deteksi kelas 
minoritas sehingga sensitivity dan specificity dapat digunakan untuk menunjukkan performa dari dua kelas. Cut off dari sensitivitas dan spesifisitas bisa digunakan untuk membuat kurva ROC untuk mendapatkan nilai dari area under curve AUC [18]. Eksperimen dilakukan menggunakan perangkat komputasi Intel core i5 gen 6 dengan operasi sistem windows 10. Development Environment menggunakan IDE R Studio 1.4 dan bahasa pemograman $R$ Language versi 4.0.5 serta menggunakan beberapa packages atau library yang tersedia di https://cran.r-project.org/.

Metode C4.5 pada Tabel 5 menunjukkan bahwa teknik oversampling memiliki performa terbaik dibandingkan dengan teknik sampling yang lain maupun tanpa resampling dengan nilai AUC 0.75. Disisi lain jika melihat hasil prediksi kebenaran kelas minoritas, oversampling berhasil mencapai 47 aktual positif namun mengorbankan nilai aktual negatif. Hal ini dikarenakan sangat sulit untuk membuat model pembelajaran yang efektif jika distribusi kelas dalam kumpulan data training yang digunakan tidak seimbang hingga berdampak pada menurunnya kinerja algoritma [10]. Metode $R F$ (Random Forest) pada Tabel 6 menunjukkan bahwa teknik over-sampling juga memiliki performa terbaik dengan nilai AUC 0.73. Jika dibandingkan dengan C4.5 metode Random forest mengalami penurunan pada kebenaran aktual positif menjadi 39 namun, kebenaran terhadap aktual negatif meningkat menjadi 77. Namun, jika dilihat secara umum metode RF memiliki performa sedikit lebih baik dari C4.5 dalam menangani masalah ketidakseimbangan kelas berdasarkan nilai AUC yang diperoleh.

Metode SVM (Support Vector Machines) pada Tabel 7 menunjukkan bahwa teknik yang menggabungkan antara under dan over-sampling memiliki performa terbaik dengan nilai AUC 0.80. Disisi lain jika melihat hasil prediksi kebenaran kelas minoritas atau kelas positif, teknik both ini berhasil mencapai angka kebenanran aktual positif sebesar 49 dan angka kebenaran aktual negatif 74. Jika diambil nilai rata-rata maka metode SVM memiliki performa lebih baik dibanding C4.5 dan RF dalam mendeteksi penyakit diabetes pada dataset Pima Indians baik sebelum menerapkan teknik resampling maupun setelah menggunakan teknik sampling.

Tabel 4 Confusion Matrix Algoritma C4.5

\begin{tabular}{|c|c|c|c|c|c|c|c|}
\hline \multirow{2}{*}{ Metode Sampling } & \multirow{2}{*}{ Prediksi } & \multicolumn{2}{|c|}{ Aktual } & \multirow{2}{*}{ Akurasi } & \multirow{2}{*}{ Sensitivity } & \multirow{2}{*}{ Specificity } & \multirow{2}{*}{$\mathbf{A U C}$} \\
\hline & & Positif & Negatif & & & & \\
\hline \multirow{2}{*}{ Original } & Positif & 33 & 9 & \multirow{2}{*}{0.7516} & \multirow{2}{*}{0.5323} & \multirow{2}{*}{0.9011} & \multirow{2}{*}{0.7167} \\
\hline & Negatif & 29 & 82 & & & & \\
\hline \multirow{2}{*}{ Over-Sampling } & Positif & 47 & 23 & \multirow{2}{*}{0.7516} & \multirow{2}{*}{0.7581} & \multirow{2}{*}{0.7473} & \multirow{2}{*}{0.7527} \\
\hline & Negatif & 15 & 68 & & & & \\
\hline \multirow[b]{2}{*}{ Under-sampling } & Positif & 36 & 21 & \multirow[b]{2}{*}{0.6928} & \multirow[b]{2}{*}{0.5806} & \multirow[b]{2}{*}{0.7692} & \multirow[b]{2}{*}{0.6749} \\
\hline & Negatif & 26 & 70 & & & & \\
\hline & & & & & & & \\
\hline \multirow{2}{*}{ Both } & Positif & 36 & 20 & \multirow{2}{*}{0.6993} & \multirow{2}{*}{0.5806} & \multirow{2}{*}{0.7802} & \multirow{2}{*}{0.6804} \\
\hline & Negatif & 26 & 71 & & & & \\
\hline \multirow{2}{*}{ ROSE } & Positif & 34 & 11 & \multirow{2}{*}{0.7451} & \multirow{2}{*}{0.8791} & \multirow{2}{*}{0.5484} & \multirow{2}{*}{0.7138} \\
\hline & Negatif & 28 & 80 & & & & \\
\hline
\end{tabular}

Tabel 5 Confusion Matrix Algoritma Random Forest

\begin{tabular}{|c|c|c|c|c|c|c|c|}
\hline \multirow{2}{*}{ Metode Sampling } & \multirow{2}{*}{ Prediksi } & \multicolumn{2}{|c|}{ Aktual } & \multirow{2}{*}{ Akurasi } & \multirow{2}{*}{ Sensitivity } & \multirow{2}{*}{ Specificity } & \multirow{2}{*}{$\mathbf{A U C}$} \\
\hline & & Positif & Negatif & & & & \\
\hline \multirow{2}{*}{ Original } & Positif & 34 & 12 & \multirow{2}{*}{0.7386} & \multirow{2}{*}{0.5484} & \multirow{2}{*}{0.8681} & \multirow{2}{*}{0.7083} \\
\hline & Negatif & 28 & 79 & & & & \\
\hline \multirow{2}{*}{ Over-Sampling } & Positif & 39 & 14 & \multirow{2}{*}{0.7582} & \multirow{2}{*}{0.6290} & \multirow{2}{*}{0.8462} & \multirow[b]{2}{*}{0.7376} \\
\hline & Negatif & 23 & 77 & & & & \\
\hline \multirow{2}{*}{ Under-sampling } & Positif & 43 & 25 & \multirow{2}{*}{0.7124} & \multirow{2}{*}{0.6935} & \multirow{2}{*}{0.7253} & \multirow{2}{*}{0.7094} \\
\hline & Negatif & 19 & 66 & & & & \\
\hline
\end{tabular}




\begin{tabular}{|c|c|c|c|c|c|c|c|}
\hline & & & & & & \\
\hline \multirow{2}{*}{ Both } & Positif & 41 & 19 & \multirow{2}{*}{0.7386} & 0.7912 & 0.6613 & 0.7262 \\
\cline { 2 - 8 } & Negatif & 21 & 72 & & & & \\
\hline \multirow{2}{*}{ ROSE } & Positif & 41 & 20 & 0.732 & 0.6613 & 0.7802 & 0.7208 \\
\cline { 2 - 8 } & Negatif & 21 & 71 & 0.732 & \\
\hline
\end{tabular}

Tabel 6 Confusion Matrix Algoritma SVM

\begin{tabular}{|c|c|c|c|c|c|c|c|}
\hline \multirow{2}{*}{ Metode Sampling } & \multirow{2}{*}{ Prediksi } & \multicolumn{2}{|c|}{ Aktual } & \multirow{2}{*}{ Akurasi } & \multirow{2}{*}{ Sensitivity } & \multirow{2}{*}{ Specificity } & \multirow{2}{*}{ AUC } \\
\hline & & Positif & Negatif & & & & \\
\hline \multirow{2}{*}{ Original } & Positif & 34 & 7 & \multirow{2}{*}{0.7712} & \multirow{2}{*}{0.5484} & \multirow{2}{*}{0.9231} & \multirow{2}{*}{0.7357} \\
\hline & Negatif & 28 & 84 & & & & \\
\hline \multirow{2}{*}{ Over-Sampling } & Positif & 42 & 12 & \multirow{2}{*}{0.7908} & \multirow{2}{*}{0.6774} & \multirow{2}{*}{0.8681} & \multirow{2}{*}{0.7728} \\
\hline & Negatif & 20 & 79 & & & & \\
\hline \multirow[b]{2}{*}{ Under-sampling } & Positif & 44 & 16 & \multirow[b]{2}{*}{0.7778} & \multirow[b]{2}{*}{0.7097} & \multirow[b]{2}{*}{0.8242} & \multirow[b]{2}{*}{0.7669} \\
\hline & Negatif & 18 & $\frac{10}{75}$ & & & & \\
\hline \multirow{2}{*}{ Both } & Positif & 49 & 17 & \multirow{2}{*}{0.8039} & \multirow{2}{*}{0.7903} & \multirow{2}{*}{0.8132} & \multirow{2}{*}{0.8018} \\
\hline & Negatif & 13 & 74 & & & & \\
\hline \multirow{2}{*}{ ROSE } & Positif & 46 & 15 & \multirow{2}{*}{0.7974} & \multirow{2}{*}{0.7419} & \multirow{2}{*}{0.8352} & \multirow{2}{*}{0.7886} \\
\hline & Negatif & 16 & 76 & & & & \\
\hline
\end{tabular}

Tabel 7 Nilai AUC (area under curve) Metode Klasifikasi

\begin{tabular}{|c|c|c|c|c|c|}
\hline \multirow{2}{*}{$\begin{array}{c}\text { Algoritma } \\
\text { Klasifikasi }\end{array}$} & \multicolumn{5}{|c|}{ Metode Resampling } \\
\cline { 2 - 6 } & Original & Over-sampling & Under-sampling & Both & ROSE \\
\hline C4.5 & 0.7167 & 0.7527 & 0.6749 & 0.6804 & 0.7138 \\
\hline Random Forest & 0.7083 & 0.7376 & 0.7094 & 0.7262 & 0.7208 \\
\hline SVM & 0.7357 & 0.7728 & 0.7669 & 0.8018 & 0.7886 \\
\hline
\end{tabular}

\section{KESIMPULAN DAN SARAN}

Sebagian studi atau penelitian terkait masalah ketidakseimbangan kelas mencoba untuk mengatasinya menggunakan pendekatan level data yaitu random undersampling dan oversampling. Pengembangan metode dalam hal untuk melakukan teknik resampling juga semakin berkembang.

Pada penelitian ini peneliti menggunakan teknik resampling dasar menggunakan salah satu library yang sering digunakan pada $R$ Language yaitu Package 'ROSE' (Random OverSampling Examples) v 0.0-4 yang di dalamnya terdapat fungsi dari teknik sampling lain yang telah kami gunakan. Performa yang dihasilkan oleh function dari paket ini memang terlihat lebih baik dari sampling standar yang ada di R. Kesimpulan dari penelitian ini dapat dilihat pada Tabel 8 dimana performa tertinggi untuk prediksi penyakit diabetes ini diperoleh dengan menggunakan teknik kombinasi over dan under-sampling (Both) dengan metode klasifikasi SVM dengan nilai AUC 0.80 .

Nilai terendah didapat oleh teknik under-sampling dengan metode klasifikasi C4.5 dengan nilai AUC 0.67. Selain itu, secara keseluruhan metode klasifikasi SVM menunjukkan performa sedikit lebih baik dibandingkan dengan metode C4.5 dan RF dalam mengatasi ketidakseimbangan kelas baik itu setelah menerapkan teknik resampling maunpun tanpa resampling. Penelitian selanjutnya sebaiknya lebih menekankan untuk melakukan pendekatan komprehensif dalam mempelajari teknik resampling baik under dan over-sampling. 
Teknik pengembangan dari under dan over-sampling bisa dilakukan seperti menggunakan teknik clustering base undersampling atau perbaikan dari metode SMOTE (Synthetic Minority Over-sampling Technique) seperti A self-adaptive robust SMOTE yang dikembangkan oleh Chen [19].

\section{DAFTAR PUSTAKA}

[1] Y. Hayashi and S. Yukita, "Rule extraction using Recursive-Rule extraction algorithm with J48graft combined with sampling selection techniques for the diagnosis of type 2 diabetes mellitus in the Pima Indian dataset," Informatics Med. Unlocked, vol. 2, pp. 92 104, 2016, doi: 10.1016/j.imu.2016.02.001.

[2] B. P. Manoj Kumar, S. R. Perumal, and N. R. K, "Type 2: Diabetes mellitus prediction using Deep Neural Networks classifier," Int. J. Cogn. Comput. Eng., vol. 1, pp. 55-61, 2020, doi: 10.1016/j.ijcce.2020.10.002.

[3] J. J. Khanam and S. Y. Foo, "A comparison of machine learning algorithms for diabetes prediction," ICT Express, no. xxxx, 2021, doi: 10.1016/j.icte.2021.02.004.

[4] S. A. Kaveeshwar and J. Cornwall, "The current state of diabetes mellitus in India," Australas. Med. J., vol. 7, no. 1, pp. 45-48, 2014, doi: 10.4066/AMJ.2014.1979.

[5] G. Swapna, R. Vinayakumar, and K. P. Soman, "Diabetes detection using deep learning algorithms," ICT Express, vol. 4, no. 4, pp. 243-246, 2018, doi: 10.1016/j.icte.2018.10.005.

[6] N. Chawla, K. Bowyer, L. Hall, and W. Kegelmeyer, "SMOTE: synthetic minority oversampling technique," J. Artif. Intell. Res., vol. 16, pp. 321-357, 2002, doi: 10.1613/jair.953.

[7] H. Hairani, K. E. Saputro, and S. Fadli, "K-means-SMOTE for handling class imbalance in the classification of diabetes with C4.5, SVM, and naive Bayes," J. Teknol. dan Sist. Komput., vol. 8, no. 2, pp. 89-93, 2020, doi: 10.14710/jtsiskom.8.2.2020.89-93.

[8] W. Nugraha, M. S. Maulana, and A. Sasongko, "Clustering Based Undersampling for Handling Class Imbalance in C4.5 Classification Algorithm," J. Phys. Conf. Ser., vol. 1641, no. 1, pp. 1-6, 2020, doi: 10.1088/1742-6596/1641/1/012014.

[9] C. Beyan and R. Fisher, "Classifying imbalanced data sets using similarity based hierarchical decomposition," Pattern Recognit., vol. 48, no. 5, pp. 1653-1672, 2015, doi: 10.1016/j.patcog.2014.10.032.

[10] W. C. Lin, C. F. Tsai, Y. H. Hu, and J. S. Jhang, "Clustering-based undersampling in class-imbalanced data," Inf. Sci. (Ny)., vol. 409-410, pp. 17-26, 2017, doi: 10.1016/j.ins.2017.05.008.

[11] M. M. Rahman and D. N. Davis, "Cluster Based Under-Sampling for Unbalanced Cardiovascular Data," Proc. World Congr. Eng. 2013, vol. 3, pp. 1-6, 2013.

[12] F. Gorunescu, Data mining: concepts and techniques. Berlin, 2011.

[13] C. Vercellis, Business Intelligence : Data Mining and Optimization for Decision Making. John Wiley \& Sons, Ltd, 2009.

[14] H. He and E. A. Garcia, "Learning from Imbalanced Data," IEEE Trans. Knowl. Data Eng., vol. 21, no. 9, pp. 1263-1284, 2019, doi: 10.1109/TKDE.2008.239.

[15] R. S. Wahono, N. S. Herman, and S. Ahmad, "A Comparison Framework of Classification Models for Software Defect Prediction," vol. 20, no. 10, pp. 1945-1950, 2014, doi: 10.1166/asl.2014.5640.

[16] I. H. Witten, E. Frank, and M. A. Hall, Data Mining Third Edition. Elsevier Inc, 2011.

[17] S. Lessmann, B. Baesens, C. Mues, and S. Pietsch, "Benchmarking classification models for software defect prediction: A proposed framework and novel findings," IEEE Trans. Softw. Eng., vol. 34, no. 4, pp. 485-496, 2008, doi: 10.1109/TSE.2008.35. 
[18] M. Kuhn, "Building Predictive Models in R Using the caret Package," J. Stat. Softw., vol. 28, no. 5, pp. 1-26, 2008, [Online]. Available: http://www.jstatsoft.org/v28/i05/paper.

[19] B. Chen, S. Xia, Z. Chen, B. Wang, and G. Wang, "RSMOTE: A self-adaptive robust SMOTE for imbalanced problems with label noise," Inf. Sci. (Ny)., vol. 553, pp. 397428, 2021, doi: 10.1016/j.ins.2020.10.013. 